\title{
Organisational Change and Development of Reformed Chinese Township and Village Enterprises
}

\author{
Weifeng Chen * \\ Weifeng.Chen@brunel.ac.uk \\ Adrian Woods \\ Adrian.Woods@brunel.ac.uk \\ Satwinder Singh \\ Satwinder.Singh@brunel.ac.uk
}

Brunel Business School, Brunel University, Uxbridge, Middlesex, UK

\begin{abstract}
Purpose: This paper investigates the organisational changes (OCs) and the development of Chinese reformed township and village enterprises (RTVEs), their marketing and R\&D strategies, and the impact of changes in terms of overall performance.

Design/Methodology/Approach: A case study methodology involving semi-structured interviews is adopted. The unit chosen is the Guotai International Group (GTIG) in Zhangjiagang, Suzhou, Jiangsu province, China, in which the organisational changes over a period of over 40 years are analysed.

Findings: OCs in Chinese RTVEs are found to be driven by a combination of local government plans and market forces. Considering the hybrid nature of the organisation and ownership structures, changes in Chinese RTVEs follow a very much ‘top-down' approach.

Research implications: The findings imply that managers appointed by the State in RTVEs usually lack the necessary skills in marketing and business management, and can be resistant to organisational changes, such as the willingness to undertake risks. As a result, RTVEs may become stuck in a cycle of low-cost, low-tech products, inhibiting any breakthrough in developing their own quality brands.

Originality/Value: This is one of few papers studying change over a long span of time to arrive at research findings that will be useful to academic researchers in their future work. The qualitative findings from this paper would also enrich the literatures on organisational change in Chinese RTVEs.
\end{abstract}

Keywords: Organisational Change, Chinese Reformed Township and Village Enterprises, Ownership Structure.

Paper Type: Research Paper 


\section{Introduction}

The Chinese government has pursued a policy of economic reform since the introduction of its Open Door Policy in 1978 (Child \& Tse, 2001; Peng, 1997). It is argued that the pace of such reforms has only increased during recent years (Nee et al., 2007; Krug \& Hendrischke, 2007; Zhou et al., 2006; Luo, 1999). China's admission to the World Trade Organisation (WTO) in 2003 is viewed as a landmark in the pursuit of an increasingly liberal economic policy. Such liberalisation exposes China's socialised economy to global market forces. Research has linked this exposure to recent increases in efficiency and competitiveness (Child, 1994). Whilst market-driven growth has become a major focus in the Chinese government, it is known that both State Owned Enterprises (SOEs) and private firms are under a varying measure of state control.

Market liberalisation has not been uniform across China; whilst China's Special Economic Zones (SEZs) and eastern coastline have been given a large measure of economic freedom, the westernmost provinces nevertheless remain under state control (Qiu, 2005). The Seventh Five-Year Plan (FYP) states that the coastal region comprises nine provinces and three centrally administrated municipalities. This region has only $16 \%$ of the land in China, but accounts for around $44 \%$ of the population. Given the dense concentration of human resources, a history of international trade and its geographical location, it follows logically that China's economically liberal SEZs are located within this region. Reviewing the economic history of the country, it can be clearly demonstrated that government policy success in this coastal area is not long after translated into national economic policy. Therefore, whilst it would be an exaggeration to claim that organisational change in SEZs and the eastern coastline region is singularly representative of China as a whole, it may nevertheless prove an important indicator of future economic direction.

Public enterprises - especially so-called township and village enterprises (TVEs) (Walder, 1995; Luo, 1999) owned and operated by village or town and municipal governments-are the unique and significant force within China's economy (Child \& Tse, 2001). The TVEs were the engines of growth of China's economy in the 1980s, generating up to half of all total value added, profit and output ( $\mathrm{Li}, 2005$; Krug \& Hendrischke, 2007). The rapid pace of organisational change amongst such Chinese public enterprises could be no clearer than in Guotai International Group (GTIG), which operates within the Zhangjiagang SEZ (Suzhou, Jiangsu, China), located at the lower Yangtze Delta. GTIG was once a purchasing and trade vehicle of the local government, but the local government now hold only approximately $30 \%$ of the share of GTIG. Whilst it may seem likely that having so few government officials working within GTIG would reduce resistance to change, western observers often underestimate their significance; therefore, during a time when GTIG has been exposed to the tremendous pressure of a global marketplace, it must also be assumed that some percentage of the choices made by GTIG's management mirror the directives of the Chinese government. The legacy of government control, the centre-planning and the new 'hybrid' format (Luo, 1999; Borys \& Jemison, 1989) of GTIG present its flexibility of change in terms of innovative and risk-taking strategies in regard to seeking business opportunities, and 
also a structural barrier to change - one that has been overlooked in research to date. Although literatures on Chinese TVEs have received increased attention (i.e. Child \& Tse, 2001; Luo, 1999; Putterman, 1997; Walder, 1995), the dynamics and organisational changes of such 'hybrid' Chinese enterprises today remain under-researched (Krug \& Hendrischke, 2007). With this in mind, the present study examines the organisational change of GTIG, a typical Chinese RTVE at the lower Yangtze Delta, and further explores the significance of the 'government-as-stakeholder' and the 'agency behaviour' of the company's senior management. The analysis following identifies the local government as a driving force behind GTIG's growth, but also as a barrier to other forms of organisational change. This is also true for the holding company, which is exposed to the increasingly dynamic environment to which its partner firms are exposed. This dichotomy has broader implications for the rest of China as well as for other transitional economies following their example.

In the next section, the literature is reviewed in order to locate this study within existing knowledge on organisational change, resistance to change, and the influence of local government in transitional economies. Our research into GTIG is presented as a case study of organisational direction and change within the Chinese SEZ context. Following the literature review, the GTIG case is examined so as to derive a theoretical model of the forces of driving and resisting the organisational changes in this company. Finally, the implications of such changes and the extent to which the local Chinese government is aware of them is discussed.

\section{Literature Review}

From the outset, it must be recognised that the strategic implications of change have probably always been a consideration of organisational life. The vast majority of what is known about the reshaping of organisational structure, co-ordination and control (Greenwood et al., 1993) is based on the classic capitalist/western market model of for-profit organisations. In the review of contemporary literature, Pettigrew et al. (2001) comment that 'the field of organisational change is far from mature', and identify several areas for further research. In particular, they call for further examination of multiple contextual variables, such as the market environments in which a firm is located, the firm's history and organisational culture, and the power and politics enabling and constraining change. A continuous and evolving view of organisational change was proposed in transitional markets, such as China (Brown \& Eisenhardt, 1997; Feldman, 2004; Tsoukas \& Chia, 2002). For instance, Brown \& Eisenhardt (1997) indicate that the ability to engage in rapid and relentless change is critical for firms to survive in highly uncertain environments; Feldman (2004) explores the role that firm resources play in building the firm's ability to change through in-depth case studies. 


\section{Hybrids of Ownership Structure of RTVE}

Developed from Freeman's (1984) conventional stakeholders theory, Friedman (2006) states that the organisation itself should be considered as the grouping of stakeholders, and the purpose of the organisation should be to manage their interests, needs and viewpoints. In the case of GTIG, the prime stakeholders are the Chinese national government, the GTIG holding company, the partner companies, and the local government of the SEZ. Following the work of the ownership of Chinese public enterprises by Walder (1995), TVEs are referred to as 'hybrid form' (Nee, 1992), where the Chinese local government holds all rights to control, income flows, and sale or liquidation-except for those rights it chooses to transfer to agents who are either hired to manage such assets or who obtain such rights in lease contracts. According to Walder (1995), the local Chinese government hires and replaces managers or otherwise allocates contracts to lease assets, and makes the ultimate decision to open or close the enterprise or shift its activity; the government has the right to all income flows from the asset, with the exception of those allocated to the managers in their incentive contracts; the government has the right to sell off an asset and that it bears responsibility for the gains or losses from that sale, and that it therefore ultimately bears all risk. However, Walder's local state corporatist view of local governments as industrial firms cannot resolve the capability constraint of government involvement at the firm level that fiscal federalism and the resulting incentive effects do not substantially affect the government's ability to actively intervene in an entrepreneurial way (Nee et al., 2007). Luo (1999) defines TVEs as rural non-state enterprises which are subordinate to township or village governments and are owned and operated collectively, and which also represent an intermediate property form shaped by rapidly changing environment where market forces are incrementally replacing the state planning mechanism and encouraging greater efficiency and flexibility in business. TVEs face hard budget constraints, which encourage more efficiency and flexibility whilst forcing them to follow the rules of the market to a greater degree than large hierarchical state enterprises (Luo, 1999).

Since TVEs, such as GTIG, were owned by community collectives represented by local governments and have access to more capital and raw materials than privately owned firms, whilst also being protected from central government interference (Nee, 1992). TVEs are therefore structurally better protected than small private firms, and institutionally more flexible than large hierarchical firms. The inter-organisational relationships between TVEs and local governments are bilaterally dependent. When the firms constitute the primary source of revenue for local governments, they also receive immense governmental assistance in financing, resource access, risk diversification, and the like. This interdependence creates transaction costs and uncertainty reduction advantages for TVEs (Nee, 1992; Luo, 1999), and spurs managers to be innovative and adaptive. 
Exposure to a global marketplace has forced Chinese managers to at least develop a level of savvy, if not full acceptance, of western management practice and expectations. This exposure is somewhat tempered by the continued use of highly centralised organisational structures (Heller, 1999), and reliance on 'Guanxi' in place of western legal contracts - even within the SEZs. Transaction Cost Theory view markets and organisations (hierarchies) as two alternative governance and coordinating mechanisms that control the exchange of goods and services, with the key for managers resting in choosing between the organisational arrangements, which achieve lower transaction costs (Teece, 1981; Williamson, 1981; Coase, 1937). Compared to the well-established market institutions, in transitional economies with relatively poor market institutions, the facility to conduct business will be improved through administrative processes imposed within organisational hierarchies through the power and authority of the executives involved. Firms operating within such emerging markets are organised into business groups, which can act as a substitute for market institutions that are missing to reduce transaction costs caused through 'institutional voids' (Khanna \& Palepu, 2000). According to Yiu et al. (2007), the focus of TC theory is directed toward internal markets and inter-firm transaction mechanisms within a group organisation, such as in the case of GTIG-especially the internal transactions of strategic factors, such as capital, information, technology and know-how, and managerial personnel.

\section{Involvement and Role of Local Government}

Whilst government involvement may vary from one company to the next, Chinese local government still controls the operating context, and in so doing can influence the behaviours of the most liberalised firm if they so choose (Child \& Tse, 2001). Fortunately for the part owners of GTIG, the goal of profitability has fully penetrated policy thinking in its SEZ. Peng (2003) states that, 'how organisations strategize during fundamental institutional transitions still remains largely unknown'.

During the course of this paper, we study a RTVE case with deep insights and accordingly argue that organisational change takes place in transitional economies, such as China, which is a result of the changing mix of stakeholder interests. The classic influence of governmental directives is now balanced by exposure to global market forces, private shareholder interests, partnership agreements, and the behaviours of lionised and western-educated senior management.

Starting in 1985, the reform of Chinese SOEs has been the key focus of governmental reform (Child, 1994). The Chinese government-which exerted absolute ownership until 1978 and strategic control until 1994-has, over the last twelve years, consistently pushed organisational restructuring and management reform. Their objective was to reduce the Chinese economy's dependence on central planning, which even the most dedicated Maoist would admit has limitations, and to accordingly increase responsiveness to market forces 
through devolved decision-making at an organisational level. As Nee et al. (2007) state, China's success is built on the gradual liberalisation of product and labour markets, increasing openness to foreign trade, investment in infrastructure and institutional reforms, such as property reforms and privatisation, which provide individual actors with sufficient security for planning, investing and economic risk taking.

Extending previous work, in this paper we study the GTIG case and argue that, whilst most organisational theory is based on a western model, the insight concerning the forces influencing organisational structure and change fit into similar generic categories - regardless of the political context. This view is supported by Hafsai \& Farashahi (2005), who argue 'that there is widespread applicability of western-based concepts of general management and organisational theories to developing countries'-especially where such concepts explore more general economic forces rather than detailed personal behaviours. With this in mind, this paper conceptualises organisational change as an outcome of the various actions, interests and relative power of stakeholders (or, in the sociological sense, agents) within and without the firm, as argued by Donaldson \& Preston (1995) in the Stakeholder Theory of the Corporation. Parallel to the increase in organisational freedom in China has been the growth of western academia's interest in Chinese organisational reform and change. Some recent studies have shed light on the changing nature of Chinese management (Nee et al., 2007; Krug \& Hendrischke, 2007; Child \& Tse, 2001; Peng et al, 2001). From this research, we can highlight the above three major themes of specific importance in terms of investigating GTIG.

\section{Research Methods}

In recent years, there have been a growing number of research papers on organisational change in China's SOEs and TVEs (i.e. Nee et al., 2007). The tradition of scientific method would suggest that an examination of factors that drive or resist change could be carried out with some sort of survey research tool or secondary data from databases; however, understanding the change of organisations means flushing out any empirical data immersed in the history of the individuals and the organisation, i.e. in the relationship linking the change phenomenon to its context (Pettigrew et al., 2001). In this paper, we examine the organisational change of a typical RTVE in China-presently the fastest-growing transition economy in the world-over a period of four decades. The complex and dynamic nature of this study has led us to adapting the single case study approach in an attempt to explore the extensive and complex organisational change of Chinese SOEs.

A case study method is widely used in management research with the objective to understand the particular phenomenon in-depth (Gummesson, 1991; Yin, 1994). There are obvious limitations on findings drawn from a single case analysis, such as the concern of generalisation and the potential bias of results; however, the single case approach allows indepth analysis of the complex and dynamic issues in the research topic, thus enabling 'the researcher to peep behind the formal aspects of organisation settings' (Bryman, 1989) and 
gain an understanding of the dynamics of the settings (Gummesson, 1991). The rules, regulations, and policies pertaining to RTVEs in Jiangsu are widely applied in other provinces (Luo, 1999); thus, GTIG may be a representative case of Chinese RTVEs.

The data collection process was carried out in three phases over a 16-month period. The first phase-spanning September 2008 to March 2009-involved collecting and reviewing secondary data from GTIG and developing a literature base for the investigation's theoretical framework; such company-specific documents included annual reports, newsletters, strategic reports, press articles, and a recent review of the company history (GTIG, 2008). These materials were obtained through close contact established by the researchers with managers/shareholders in GTIG. Importantly, this preliminary information collection enabled the authors to identify the key issues for the research, thereby forming a basis for the design of the semi-structured interview.

The second phase was carried out in April and September 2009 at the headquarters of GTIG in Zhangjiagang, Suzhou, China. Ten in-depth interviews were conducted with five managers, four of whom are either general managers or deputy general managers of the four functional departments of GTIG (Finance, Investment, Planning, and Administration Office). The other five interviews were conducted with general managers from subsidiaries (See Table 1 below). All the interviewees were employees of at least five years' standing, with most having over ten years' service. Moreover, all of the subjects experienced the recent organisational change in GTIG, and have been directly involved in strategy formulation. In addition, most were directly involved in the design and implementation of the establishment of the new management model in GTIG. With the exception of their knowledge and views on the questions asked, the interviewees were encouraged to elaborate on the process and complexities of the organisational changes experienced inside GTIG. They were also invited to verify the information provided by prior interviewees and to clarify issues in contradiction and confusion. Importantly, participation in the interviews was voluntary, and the anonymity of the respondents was guaranteed.

Table 1: Details on Interview Participants

\begin{tabular}{|lllll|}
\hline Participants & Age & Gender & Experience with GTIG & Position \\
\hline HQ Manager 1 & 57 & Male & 15 years & General Manager \\
HQ Manager 2 & 45 & Female & 8 years & Finance \\
HQ Manager 3 & 50 & Male & 10 years & Planning \\
HQ Manager 4 & 41 & Male & 6 years & Investment \\
HQ Manager 5 & 56 & Male & 18 years & Administration \\
Subsidiary Manager 1 & 38 & Female & 6 years & Subsidiary Manager \\
Subsidiary Manager 2 & 40 & Male & 6 years & Subsidiary Manager \\
Subsidiary Manager 3 & 35 & Male & 5 years & Subsidiary Manager \\
Subsidiary Manager 4 & 51 & Female & 7 years & Subsidiary Manager \\
Subsidiary Manager 5 & 43 & Male & 5 years & Subsidiary Manager \\
\hline
\end{tabular}


The third phase of data collection occurred after September 2009. During this stage, frequent information exchange with mangers in GTIG through emails, telephone calls and online communications through Skype was examined. Our informants not only include mangers (former interviewees) but also some middle managers from subsidiaries; this was to fill in any gaps identified after the field visit, to clarify conflicting information, and to accordingly incorporate data on issues ignored during interviews in the previous stages.

Interview scripts and field notes were analysed using standard content analysis methods (Krippendorff, 2004; Holsti, 1969).This involved recording data on the milestones of GTIG's development and the key dimensions of the organisational change at GTIG, such as the repeated changes of control leadership between the local government and GTIG, and also between GTIG and its subsidiaries, as well as the steps that GTIG has taken in pushing for organisational change. Such data were then structured to address the research topic. Emerging themes were further pursued to extract leads for understanding the forces for Organisational Change and Development (OCD) in GTIG. In the case analysis, this evidence is presented in summary and to-date (May, 2010).

\section{Case Analysis}

Guotai International Group (GIG) is one of the largest foreign trade groups in China. A national and international foreign trade enterprise, GTIG trades in numerous products, including textiles, garments, handicrafts, hardware, chemicals, pharmaceutical, steel, ships, and so on. Moreover, it is involved in many different international projects, such as labour service, international logistics, and shipping consultancy. In addition, GTIG provides software development, finance consultancy, real estate, hotel and travel. At present, GTIG owns 16 import/export subsidiaries, over sixty manufacturing enterprises, two five-star hotels, and overseas branches in the US, Japan and Hong Kong, employing up to 13,000 staff. GTIG's total assets exceed 3 billion RMB. In 2006, the group's sale amounted to 15.25 billion RMB, whilst the total import and export value was up to $\$ 1.36$ billion-including $\$ 1.2$ billion of exports. As the largest trading company in the Group, Guomao Corporation was also listed in the Shenzhen Stock Exchange House on December 8, 2006 (Stock Name: Jiangsu Guotai; Code: 002091). Table 2 below shows the profits GTIG from 2002-2008.

Table 2: GTIG Profit Year 2002-2008

\begin{tabular}{|lc|}
\hline Year & Profit (Million RMB) \\
\hline $\mathbf{2 0 0 2}$ & 7374.89 \\
\hline $\mathbf{2 0 0 3}$ & 10380.73 \\
\hline $\mathbf{2 0 0 4}$ & 12062.62 \\
\hline $\mathbf{2 0 0 5}$ & 14048.26 \\
\hline $\mathbf{2 0 0 6}$ & 15246.75 \\
\hline $\mathbf{2 0 0 7}$ & 16776.55 \\
\hline $\mathbf{2 0 0 8}$ & 18210.02 \\
\hline
\end{tabular}


After more than thirty years since its inception, GTIG has become the number one foreign trade enterprise in Jiangsu province, China. GTIG acquired its first independent Import \& Export License in 1992. In 2005, GTIT exports stood at US\$108 million, and was the largest exporter amongst foreign trade enterprises in Jiangsu province for five successive years. Clearly, GTIG has come a long way since it was a just purchasing unit of the government when first established in 1973.

GTIG is one of the top 200 'free' enterprises in China today. Behind these achievements, however, powerful political and structural change is evident. Accordingly, this paper asks: now fully exposed to global markets with increasingly savvy local investors and demanding international customers, what will shape GTIG in the near future? Is it following an international model for development within a transitional economy? Are there forces that will resist the 'organic' change we might expect in the west? Does a consideration of these factors tell us why GTIG's structure looks as it does today?

Since its establishment in 1973 - and until as recently as 1998 - GTIG had been under the full direct control of the local government. It was originally designated as the agent of procurement for the local government in the city Suzhou. During 1973-1992, GTIG was a combination of government organisation and monopolistic business operator. This dual role insured that GTIG was not only a traditional SOE - and therefore part of the public sectorbut also a service provider endowed with a business structure. Prior to 1998, the governmentappointed leadership of GTIG determined that its business operations were always politically oriented as opposed to profit-based. Markedly, GTIG was a classic component of the national planning system, and played this role for its first 20 years.

China's economic reform in 1978 enabled the central government to push SOEs to transform themselves into business operators. Initially, the government attempted to implement reform through a series of incremental changes. GTIG responded but did so without undertaking fundamental transformations within its organisation and internal culture. The Chinese government opened up the market to foreign trade in 1984 and accordingly introduced competition into this industry. GTIG was encouraged to change to keep up with the domestic market environment; however, this does not mean that GTIG was an independent business operator. The local government continued its intervention in GTIG's operations, as it was since it was founded. After acquiring the Import and Export Licence in 1992, Zhangjiagang foreign trade company and local foreign trade company were merged as a group, which was then named GTIG. By the end of 1996, the turnover of the group reached US $\$ 0.432$ billion, and GTIG became positioned in the top fifty foreign trade enterprises in China. The organisational reform was locally considered a significant success.

When GTIG was selected to be one of the 120 SOEs pioneering a new wave of organisational reform in 1997, the management and related business partners of GTIG were empowered to undertake radical organisational reconstructing with the full support of government; this was outlined in an official document issued by the local government entitled 'Ownership Transformation, Share Issue, and Development of GTIG and Subsidiaries 1997' (Suzhou 
Government Archives, 1997). At this point, the management of GTIG started its new life as a profit-driven business enterprise in foreign trade.

Table 3: Milestones of Organisational Changes in GTIG

\begin{tabular}{|c|c|}
\hline Year & Organisational changes \\
\hline 1973 & Established as procurement unit of local government \\
\hline 1992 & $\begin{array}{l}\text { Became the first company that acquired Import \& Export License in Jiangsu Province, } \\
\text { became a foreign trade group controlled by local government }\end{array}$ \\
\hline 1997 & $\begin{array}{l}\text { Change name to Guotai International Group, headquarters restructuring started with the } \\
\text { establishment of a new Board of Directors. The group is formed by } 26 \text { subsidiaries and } \\
\text { enterprises }\end{array}$ \\
\hline 1998 & Restructuring of subsidiaries \\
\hline 2003 & The Chinese Communist Party committee of GTIG was formed \\
\hline 2006 & $\begin{array}{l}\text { The largest trading company in the Group, Guomao corporation was also listed in the } \\
\text { Shenzhen Stock Exchange House in Dec 8, 2006. (Stock Name: Jiangsu Guotai; Code: } \\
\text { 002091) }\end{array}$ \\
\hline
\end{tabular}

All respondents viewed the shift in national government policy towards enterprise as the major driver of organisational change in GTIG. The adoption of market-oriented economic reform by the Chinese government resulted in fundamental change in the relationship between government and enterprise. According to Fang (1999), SOEs are regarded as the backbone of the 'socialist market economy'; however, SOEs must now follow market principles following the processes of the structure reform; this being said, most top-level managers of SOEs in China are government appointed (Groves et al., 1994). At the end of the 1980s, the Chinese government encouraged SOEs to become pure business operators and to compete with local and foreign invested enterprises following China's application to the World Trade Organisation (WTO). Under such circumstances, GTIG undertook further organisational change in an attempt to establish itself as a competitive business operator supported by the local government. During interviews, it was revealed that the single most important objective of reorganisation was profit maximisation. The local government reaped the benefit of a tax windfall, and small business people who had acquired ownership of local subsidiaries were allowed to benefit from growth like never before.

In 1997, the Chinese government introduced new policies in regard to SOEs' organisational reform in an attempt to improve competitiveness within the domestic market, which included share issue and partial privatisation of assets, which subsequently triggered organisational change in GTIG. The following excerpt is instructive:

'The competition from other local and foreign companies threatens our position in the foreign trade business. There are lots of legally registered firms nationally in our business, and there are more illegal ones doing the same job. We have managed well because of our ability to change. However, this will not continue if we don't have an effective solution to keep experienced middle managers and develop an independent long-term plan.' (HQ Manager 5) 
The above suggests that the management system within GTIG is not yet strong enough to enable it to achieve continuous success in the Chinese market independent of its local government links, and is therefore, to some extent, driven by old loyalties and objectives. It also indicates that knowledge-sharing between experienced key workers and top-level management is rare in GTIG.

\section{Structural Changes in GTIG}

From our analysis of the case material, it can be stated that comments concerning GTIG's change in organisational structure can usefully be divided in two categories: those that refer to the change in the relationship between the local government and GTIG, and those that expose the reconfiguration of the headquarter-subsidiary structure.

\section{GTIG and Local Government}

Government-led organisational change - which began in earnest in 1992 - focused on the transformation of the interventionist relationship into a non-interventionist equity-based relationship. The government redefined its role to become the regulator and the sole investor in GTIG. However, the management of day-to-day business operations was transferred to the managers of the individual firms, which do not serve the government. The top management of GTIG were nevertheless still selected by the local government, and the strategic decisions of the management were still subject to government interference. As one of the managers told us:

'... after the process of the privatisation, the role of the government has changed a lot compared to before. We are appointed by the local government to support GTIG's growth and development. We always encourage the companies in the group to expand. They do not need to consult or report us on their decisions on business deals unless they want to...' (HQ Manager 1)

After 1997, GTIG adopted its new role as a government-favoured business operator in the foreign trade industry; it was no longer part of the government and had to earn its place in business. The government maintained two links with the new entity: a management appointee, who sits on the Board of Directors, and the 25\% share of GTIG, which it retained (making it the biggest single shareholder). The government sent its representative to sit on the Board of Directors and, based on its part-ownership, guided the appointment of managers to fill the top positions of GTIG. This suggests that the government maintained strategic control over GTIG (Martinsons, 1999), but it also meant that GTIG had a subsidised and favourable business position. 


\section{Headquarter-Subsidiary Relationship inside GTIG:}

The pre-1997 organisational structure of GTIG (see Figure 1) can be linked with three barriers to organisational change and development (OCD). The first problem is that it resisted the market-led development of the subsidiaries; thus, the subsidiaries were only required to meet the target from headquarters, with subsidiary managers stating that it, 'discouraged them to try anything new'. Second, the response to the market requirement of GTIG was not quick owing to the centralised decision-making structure. The marketing strategy had been sent to the government and approved prior to its execution, which would, from a western perspective, decrease GTIG's market sensitivity. Third, many of the independently successful subsidiary managers were head-hunted by other private companies and therefore left GTIG. GTIG lost a number of important clients owing to the lack of strategy to retain experienced managers post-1997.

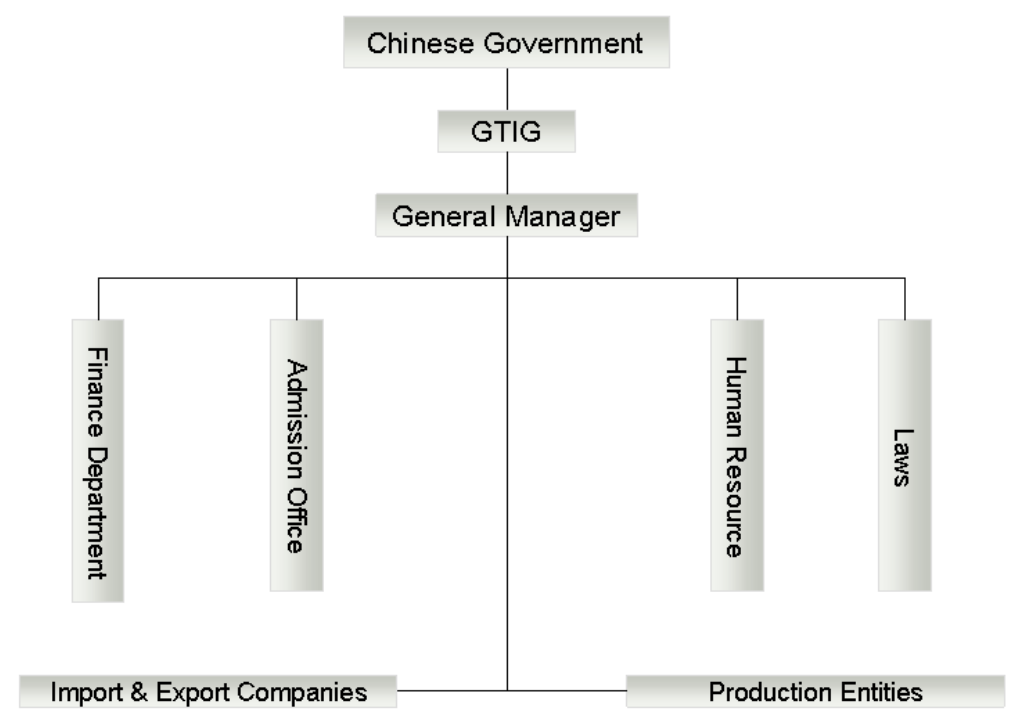

Figure 1: The Organisational Structure of GTIG before 1997

The following excerpt explains the above sentiments:

'... Before 1997, the government made all the strategies for GTIG. Our job was to meet the target planned by the top management. Now, as a shareholder of this company, we make the strategies that are suitable for our company. We need to report them to the government. People from government will have a meeting with us and we will make decision together...' (HQ Manager 3)

Following 1997, GTIG restructured yet again (Figure 2). As a shareholder of GTIG, the government no longer dominated the business processes and decision-making; in actual fact, the role of local government changed to assist the Board of Directors of GTIG in terms of dealing with the often complicated and restrictive national econo-legal system. There is still a 
general manager nominated by the government (see Control Commission block, Figure 2), but as employees and managers became shareholders of the enterprise, enthusiasm for personal gain through hard work and efficiency took hold, which also reduced the number of experienced managers willing to leave GTIG. More private companies joined GTIG as shareholders/subsidiaries. The enterprise has grown steadily since the implementation of such changes. GTIG also enlarged its business to tertiary industries and opened overseas branches in an attempt to establish more opportunities in the competitive global markets.

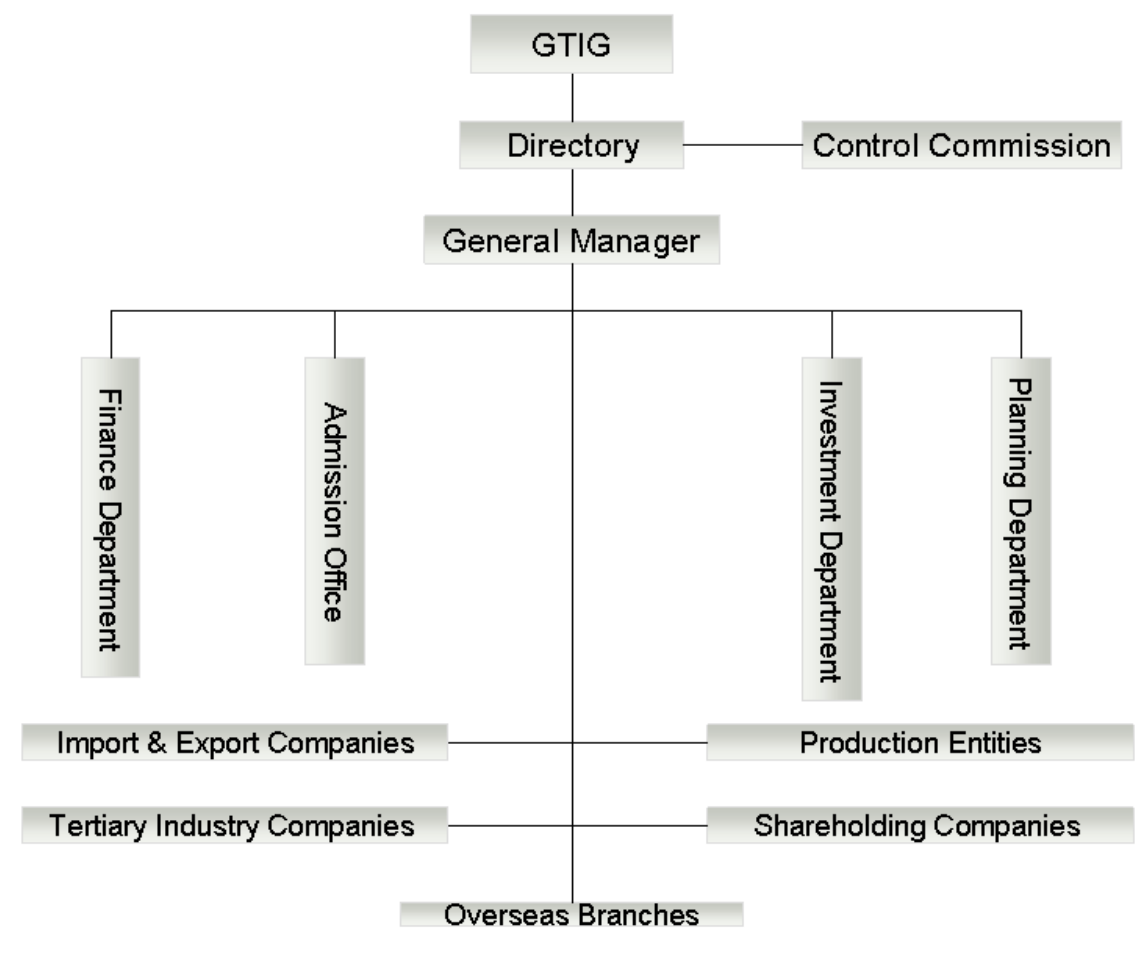

Figure 2: The Organisational Structure of GTIG after 1997

Again, the following excerpt is instructive:

'The role of the government is to guide the development direction of GTIG. The employees in GTIG before were mainly arranged by the government. After the subsidiaries of GTIG became a private limited company, the process of selecting the employees is operated inside the firm. Managers in our firms have the power to control the employment of employees which improved the employees' work efficiency. Government no longer controls the human resource of the subsidiaries anymore. As a representative of the government, the general manager in GTIG takes part in the policy-making of GTIG. His job function does not involve the control of the human resource and other business process operations in the head office and subsidiaries....' (Subsidiary Manager 4) 
After China entered the WTO, the global market environment forced local firms to change. The Chinese government encouraged OCD, to some extent, in the sense of releasing more power of controlling the business process operations of GTIG. Subsequently, this increased the flexibility and efficiency of the GTIG to survive in the dynamic global market.

'...Comparing to the rapid growth of revenue in GTIG, the management system in GTIG is rather undeveloped. The resistance to the change of management system in GTIG is from the top management of GTIG. The R\&D in GTIG is in the corner of the table that has been ignored by the top management. Although our government is starting to proclaim the importance of $R \& D$, there are still lots to be done...' (Subsidiary Manager 5)

Before the Chinese government released the control of the GTIG, R\&D was operated in other government body or companies; however, the situation changed after 1997. GTIG has to develop its own R\&D strategy, although it seems that the top management focus more on the short-term output than the long-term output; this forces them to ignore R\&D in GTIG. Essentially, this could be caused by pressure from the Chinese government, although specific reasons for this are part of on-going investigation.

\section{Corporate Culture}

Before the organisational change in 1997, GTIG's corporate culture was a combination of communist ideals and slogans concerning higher productivity and output. Being part of the government, employees were educated to serve the country and the communist party; they had no motive to develop - as opposed to simply grow - the company in ways that a western organisation of the same period might.

In the 1990s, the notion of corporate culture designed to motivate employees in promoting firm competitiveness was recognised by the management of GTIG; many feel this was as a result of the dissemination of western management practices in the wake of extensive foreign direct investment into China ( $\mathrm{Ng}, 1998)$. The management team in GTIG came to realise that resistance to organisational change was found at many levels of the organisation owing to its long history of being state-owned and centrally planned. Without an updated corporate culture cognate with the challenging market and its corporate strategy, the success of its organisational change and the development of its new management model would be unattainable (Schein, 1992). Although a renewed corporate culture is recognised as having the capacity to facilitate organisational change and play an even more significant role in containing resistance to change in such circumstances, the top management nevertheless incorrectly thought that a new corporate culture could be introduced immediately, and from above, as it had done in the past.

'The most important mission for us at the moment is to improve the cooperation of operations and management inside GTIG. Some mangers cannot control the operations 
processes in the trading because lots of trade operations processes are totally controlled by only one or a few people. If the top management are not able to manage this issue properly, it will affect the decision-making processes and cooperative strategy in GTIG. There is a fear that if this problem cannot be solved properly, GTIG will collapse into a number of private foreign trade companies...' (HQ Manager 3)

The top management of GTIG did attempt to change its corporate culture, and regarded managing its corporate culture as a crucial aspect of the overall organisational change strategy. The renewed corporate culture was intended to be a set of new norms and values centred on quality, cooperation, efficiency, and customer satisfaction, which was a complete change of mindset amongst the employees regarding the business operations of the firm.

The evidence indicates that GTIG did not fully achieve its objective with respect to using corporate culture to facilitate change. As interviewees pointed out, equipping all employees with this new corporate culture and applying it within operations remains a distant goal.

'Everybody wants to play safe instead of considering change. The leadership here is hesitant to make big changes for fear of mistakes. Lots people prefer not sharing their ideas and knowledge with others to keep themselves in a competitive position in the company ... the concept of quality and customer service is far from being in the mindset of everyone. We predominantly consider production, profit, and our old business alliances. These seem to be the biggest objective of the local government and top management.' (HQ Manager 4)

We can see that, for firms in a transitional economy, culture elements play the same important role as structure, control and strategy (Deshpande \& Farley, 2000). Following China's admission to the WTO, foreign and local firms competed directly following the removal of restriction. Culture change may become a valuable tool for Chinese former SOEs to decrease the development gap between foreign and local operators. Importantly, the wider use of corporate culture could be a way of motivating employees to consider more than mere production. In the absence of progress on this front, Hybrids, such as GTIG, will be placed at a competitive disadvantage owing to the fact that foreign and domestic firms utilise technology, innovation, knowledge and Human Resources to strengthen their position in the market.

\section{Discussion and Conclusions}

In western countries, OCD driving forces tend to have a roughly concurrent impact on organisational change. In this context, the forces, actors, ramifications, impediments, and models of change are relatively well-known. In developing or transitional countries, the same applies but in a slower pace-possibly owing to their lack of experience with such forces. One significant commonality between Chinese hybrids and nascent eastern European firms- 
notably an un-hypothesised outcome of our research - is the growth/profit imperative as overpowering operating consideration.

In China, the rate of growth is faster (average $9 \%$ in the past decade) than in western countries, although this growth remains heavily mediated by national and local authority planning as opposed to being market-driven; even though other research suggests that this would start to become less the case. For many developing countries, limiting factors do not usually include local or national government restrictions. Whilst India might have just as much 'red tape', there are no specific national plans for the restriction of private industry growth. In China, constant local and national governmental involvement was found-an increasingly uncommon business-operating context. For Chinese firms which have only recently become exposed to the capitalist market system, there is much benefit from taking advice, funding, and favour from former governmental officials - a body amongst the best educated and familiar with the complex home context. However, it is considered that such an approach also has its disadvantages, with many commenting that selling its labour cheap without home-grown OCD is a wasted opportunity.

Within this approximately forty-year-old context, we explore a relatively new Chinese and, to some extent, international business type, referred to as a hybrid firm for its mix of owners, strategy, and management team. In the case of GTIG, this means a hybrid business: a senior management team with a governmental appointee, a market-driven strategy made actionable through the use of traditional connections ('guanxi'), and a federation of subsidiaries in a style more common in Japan than anywhere else.

Our interviews from GTIG and its subsidiaries lead us to draw the following conclusions. First, the company is fully aware of the global market, which acts as a force for organisational change; in fact, each of the major market forces discussed in the interviewsincluding technology, competition, strategy, and post-central planning people managementare considered significant by GTIG's top management team. Markedly, local subsidiaries are less exposed, but are familiar with these forces. Nevertheless, local firms are more likely to take OCD direction from their parent firm rather than from their own management information system. More than anything else, OCD is driven by the desire for growth, which is of common interest to all stakeholders in GTIG. Each stakeholder tends to benefit from growth, and so we find OCD to be most fluid and facilitated around this point.

Thus, who controls the trajectory of OCD in GTIG? We would argue that GTIG, like other Chinese 'hybrid' RTVEs, OCD is controlled by the stakeholder-agency behaviour of the top management team. Within this team, the interests of the owners and local affiliates are used to consider moves within an international marketplace, although these moves are tempered by consideration of the national policy and interests that enabled GTIG to become independent in the first place, as well as by local government, which acts as a facilitator (with their own motives for GTIG's success). OCD in GTIG is therefore the product of informal institutions - more specifically 'guanxi' - and the drive for gaining a foothold in the global market place. With this in mind, the question is posed: does this mean GTIG has true independence from the Chinese government? The answer is no, nor is it similar to SOEs or 
even IJVs. It certainly operates like industry in no other transitional country; in fact, it is more similar to its Japanese and Korean neighbours despite the overwhelming capital investments of North American and European firms.

Relationships between top management behaviours and local Chinese government policy may be clear but are not solely dependent on dominant socialism; rather, they are historic cultural networks with the People's Republic of China (PRC) as happenstance grandfather figure at this point in time. As for Chinese SOEs, PRC policy drives change, but so do individual needs - a fact of which the PRC is not ignorant. International management technique is considered but not duplicated as local development is based on the perspective of what is needed for those who have an interest.

\section{Research Implications, Limitations and Avenues for Future Research}

Our research for this paper has established that Chinese RTVEs are driven by a combination of local government plans and market forces. Given the hybrid nature of organisational and ownership structures, changes in Chinese RTVEs follow a very much 'top-down' approach. This finding implies that managers appointed by the State in RTVEs usually lack the necessary skills in marketing and business management, and can be resistant to organisational changes, such as the willingness to undertake risks. As a result, RTVEs may become stuck in a cycle of low-cost, low-tech products, thus inhibiting any breakthrough in developing their own quality brands.

This paper has the strength in that it is a detailed investigation over a very long period of time on an important topic of organisational change. The limitation is that this study could be benchmarked with comparable economic data on Chinese reformed TVEs. Additionally, whilst part of an on-going longitudinal study, we realise that our investigation into GTIG has exposed various important new data concerning the forces for OCD in the new Chinese hybrid firm context. Although we intend to continue this work, we also feel this paper exposes the need for at least two other areas of investigation. First, there is the need to quantify the extent of this 'hybrid' phenomenon. Exposing the number of cases and variants would also enable a broader study of hybrid firms and their development trajectories for patterns that support or deny our claims as to what drives OCD. Second, we would like to see a detailed examination of how these 'top' social networks, such as GTIG's management team, get their information for OCD-type decisions. It is recognised that this would help to further expose a national trajectory, and could also assist in contrasting China's transitional development from those of other nations. 


\section{References}

- $\quad$ Brown, S.L. and Eisenhardt, K.M. (1997) 'The Art of Continuous Change: Linking Complexity Theory and Time-Paced Evolution In Relentlessly Shifting Organizations', Administrative Science Quarterly 42(1): 134.

- $\quad$ Bryman, A. (1989), Research Methods and Organizational Studies, London: Unwin Hyman Press.

- Buckley, P.J., Clegg, J., Tan, H. (2005) "Reform and Restructuring in a Chinese State-Owned Enterprise: Sinotrans in the 1990s", Management International Review, Vol. 45 No. 2. pp 147 - 172

- Child, J. (1994), Management in China During the Age of Reform, Cambridge: Cambridge University Press 1994.

- Child, J., and Tse, D. K. (2001), “China's Transition and Its Implications for International Business", Journal of International Business Studies, Vol. 32 No.1. pp 5-21.

- Coase, R. (1937). 'The Nature of The Firm'. Economica, 16, 386-405.

- Deshpande, R. and Farley, J. U. (2000), "Market-Focused Organizational Transformation in China", Journal of Global Marketing, Vol. 14 No. 1. pp 7-35.

- Donaldson, T. and Preston, L. E. (1995) "The Stakeholder Theory Of The Corporation: Concepts, Evidence And Implication". Academy of Management Review, Vol. 20. pp 65 - 91

- $\quad$ Fang, T. (1999), Chinese Business Negotiating Style, London: Sage 1999.

- Feldman, M.S. (2004) 'Resources In Emerging Structures And Processes Of Change', Organization Science 15(3): 295-309.

- Freeman, R.E (1984). "Strategic Management: A stakeholder Approach". Boston, MA: Pitman

- Friedman, A.L. and Miles, S. (2006). "Stakeholders: Theory and Practice", Oxford University Press.

- Greenwood, R. and Hinings, C. (1993), "Understanding Strategic Change: The Contribution of Archetypes", Academy of Management Journal, Vol. 36 No. 5. pp 1052-1081.

- Groves, T., Hong, Y., McMillan, J. and Naughton, B. (1994), "Autonomy and Incentives in Chinese State Enterprises”, Quarterly Journal of Economics, CIX, Vol. 1. pp 183-209.

- $\quad$ GTIG Company reports, 2003

- Gummesson, E. (1991), Qualitative Methods in Management Research, Sage Publications, Thousand Oaks, CA

- Hafsai, T. and Farashahi, M. (2005), "Applicability of Management Theories to Developing Countries", Management International Review, Vol. 45 No. 4. pp 483-511.

- Heller, R. (1999) Wake-up Call for the Sleeping Giant, Management Today, 29-31.

- Holsti, O. R. (1969).Content Analysis for The Social Sciences and Humanities. Reading, MA: AddisonWesley.

- Khanna, T. and Palepu, K. (2000). 'Is Group Affiliation Profitable In Emerging Markets? An Analysis Of Diversified Indian Business Groups'. Journal of Finance, 55, 867-92.

- Krippendorff, K., (2004). Content Analysis: An Introduction to Its Methodology. Beverly Hills, CA: Sage Publications

- Krug, B. and Hendrischke, H. (2008), Framing China: Transformation and Institutional Change through Coevolution. Management and Organization Review, 4: 81-108Li, P. P. (2005) The puzzle of China's township-village enterprises: The Paradox Of Local Corporatism In A Dual Track Economic Transition. Management and Organization Review, 1:197-224

- Luo, Y. (1999) "Environment - Strategy - Performance Relations in Small Business in China: A Case of Township and village Enterprises in Southern Asia", Journal of Small Business Management, Vol. 37 No. 1. pp $37-51$

- $\quad$ Luo, Y. (2001), China's Service Sector, Copenhagen: Copenhagen Business School Press 2001.

- Martinsons, M. G. (1999), "Management in China After Two Decades of an Open Door Policy", Journal of Applied Management Studies, Vol. 8 No. 1. pp 119-126.

- Nee, V. (1992) Organizational Dynamics of Market Transition: Hybrid Forms, Prop- erty Rights, and Mixed Economy in China. Administrative Science Quarterly 37 (March): 1-27.

- Nee, V., Opper, S., and Wong, S. (2007) "Developmental State and Corporate Governance In China". Management and Organization Review, 3: 19-53.

- Ng, R. M. C. (1998), "Culture as a Factor in Management: The Case of the People's Republic of China", International Journal of Management, Vol. 15 No. 1. pp 86-93.

- Oi, J. (1992) Fiscal reform and the economic foundations of local corporatism in China. World Politics, 45: 99-126.

- $\quad$ Peng, M. W (1997), "Firm Growth in Transitional Economies: Three Longitudinal cases from China, 198696”, Organization Study, Vol. 18 No. 3. pp 385-413. 
- Peng, M. W. (2004) “Outside Directors and Firm Performance during Institutional Transitions”, Strategic Management Journal, Vol. 25 No. 5. pp 453 - 471

- Peng, M. W., Lu, Y., Shenkar, O. and Wang, D. Y. L. (2001), "Treasures in the China House: A Review of Management and Organizational Research on Greater China”, Journal of Business Research, Vol. 52. pp 95-110.

- Peng, M.W. (2003) 'Institutional Transitions and Strategic Choices', Academy of Management Review 28(2): 275-296.

- $\quad$ Pettigrew, A.M., Woodman, R.W., and Cameron, K.S. (2001), "Studying Organizational Change and Development: Challenges for Future Research", Academy of Management Journal, Vol. 44 No.4, pp.697713.

- Putterman, L. (1997) “On the Past and Future of China's Township and Village-Owned Enterprises", World Development, Vol. 25, No. 10, pp. 1639 - 1655

- Qiu, Y. (2005), "Problems of Managing Joint Ventures in China's Interior: Evidence from Shaanxi, S.A.M", Advanced Management Journal, Vol. 70 No. 3. pp 46-58.

- Schein, E. H. (1992), Organizational Culture and Leadership, 2nd Ed. San Francisco: Jossey-Bass Publishers

- $\quad$ Suzhou Government Documents Archives, 1997

- Teece, D. J. (1981). 'Internal Organization and Economic Performance: An Empirical Analysis of The Profitability Of Principal Firms'. Journal of Industrial Economic, Vol. 30, pp 173-99.

- Tsang, E. (2003) "Resistance to Restructuring in Sino-Foreign Joint Ventures: Toward A Preliminary Model", Journal of Organizational Change Management, Vol. 16 No. 2. pp 205-222

- Tsoukas, H. and Chia, R. (2002) 'On Organizational Becoming: Rethinking Organizational Change', Organizational Science Vol. 13, No.5, pp 567-582.

- Walder, A. (1995). Local Governments As Industrial Firms: An Organizational Analysis Of China' Transitional Economy. American Journal of Sociology, Vol. 101, No. 2, pp 263-301.

- Williamson, O. (1981). 'The Modern Corporation: Origins, Evolution, Attributes'. Journal of Economic Literature, Vol. 19, pp 1537-68.

- Yin, R. K.(1994), Case Study Research: Design and Methods, 2nd edition, London: Sage.

- Yiu, D. W., Lu, Y., Bruton, G. D. and Hoskisson, R. E. (2007), Business Groups: An Integrated Model to Focus Future Research. Journal of Management Studies, Vol. 44, pp 1551-1579

- Zhou, K. Z., Tse, D.K., and Li, J.J. (2006) "Organizational changes in emerging economies: drivers and consequences”, Journal of International Business Studies Vol. 37. pp 248-263 